\title{
Préservons nos rites ancestraux Wôbanaki
}

Réjean Obomsawin ${ }^{1}$

\section{BIENVENUE, KOLIPAIÔ, BEM-VINDO, WELCOME}

Sur le territoire ancestral de la nation des Abénakis en mémoire de nos ancêtres respectifs qui ont vécu ensemble en harmonie depuis plusieurs générations.

Je remercie M. Bruce Gilbert, Professeur de philosophie, art libéral et justice sociale de l'université Bishop d'avoir organisé et nous avoir invités, ma conjointe Jacinthe Laliberté et moi, ainsi que tous ceux et celles qui collaborent et participent à de faire de cet événement historique un franc succès en territoire Abénakis.

II est très important de comprendre que d'être Abénakis et de pratiquer, de protéger et de conserver nos traditions, nos coutumes et nos cérémonies n'est pas du tout l'image qui est véhiculée. Ma communauté entre autres est un exemple flagrant de l'impact de la « Loi sur les Indiens » et les différentes manières d'acculturer un peuple. Ce n'est pas toujours des erreurs commises par des allochtones, mais l'influence politique et sociale d'autochtones qui n'ont malheureusement pas connu la beauté des traditions orales, les contes, les légendes qui sont l'âme de ma communauté, ce qui ne s'achète pas, mais se mérite.

1 Wawasi Piônisak (Chef Spirituel). Conférence présentée au Colloque Droits Sociaux et Environnementaux à l'université Bishop. Odanak, Le 20 octobre 2017. 
Auparavant, l'esprit d'entraide était une pratique commune de nos coutumes. Maintenant j'ai découvert à ma grande surprise que des classes sociales existent toujours à Odanak. Cette nouvelle façon de penser et d'agir fut instaurée par des individus, étrangers à notre culture, et qui se sont introduits de différentes façons, soit par le commerce de la vannerie ou tout simplement par le mariage, afin d'avoir accès à des positions politiques importantes de ma communauté. Cette manière de penser et d'agir est palpable et se manifeste soit par le contrôle de l'économie, la médisance, l'individualisme, tout en s'assurant que les valeurs basées sur le Sacré selon nos enseignements ne soient pas accessibles et ainsi, détruire des sites Sacrés comme celui près de ma demeure en septembre 2017. Ce genre de manières envoie un message très clair pour les générations futures disant que les traditions du Sacré ne sont pas les bienvenues dans notre communauté. Ils affirment à notre communauté de façon imposante que cela appartient au passé que maintenant, c'est devenu du folklore pour les touristes. C'est de cette façon qu'ils affirment à l'auditoire général, que nous avons oubliés nos traditions, ce qui est faux.

Je crois plutôt qu'il est toujours d'actualité de faire revivre et sortir de l'ombre les pratiques du sacré Abénakis et autres. La réconciliation doit se faire dans notre communauté pour et par notre peuple. J'ai découvert au fil des années que de découvrir la personne que je suis et mes origines Franco-Abénakis font partie d'un «tout» de ce que je suis, en tant qu'être humain et de vivre en harmonie avec tout ce qui m'entoure. Notre histoire, nos traditions, nos rites et notre territoire contiennent beaucoup de trésors à découvrir et à protéger pour les générations futures et le chérir avec d'autres nations qui nous honorent par leurs visites sur le territoire Abénakis.

Je suis très fier de pouvoir échanger avec vous à propos de ce que nous sommes et de ce que j'ai appris de nos traditions et cérémonies depuis les trente dernières années.

\section{INTRODUCTION}

Dans ce présent énoncé, j’aborderai la période pré-contact qui décrit les déplacements sur le territoire pour les besoins de notre peuple 
Abénakis et la période contact qui relate les premières rencontres avec les Européens et leur structure du territoire que nous avons adopté. Je décris aussi la reconnaissance des Abénakis par la France en 1750 et l'acceptation des Abénakis devenus des seigneurs sur leurs terres, de concéder par location des terres aux colons aux fins d'agriculture et de besoins résidentiels. Entre temps, est survenue la guerre de 1812 entre le Canada et les États-Unis. Je poursuis en décrivant l'origine des Abénakis et leurs mœurs. Pour terminer, je vous parlerai de mon apprentissage et pratique des cérémonies sacrées ancestrales, ainsi que mes motivations à vouloir conserver notre culture et coutume qui se fragilisent par des actions irréfléchies de la part de certaines personnes.

\section{PÉRIODE PRÉ-CONTACT}

La nation Abénakis vit sur le territoire depuis des temps immémoriaux soit, plus de douze miles ans. Les dernières fouilles archéologiques (2008) au site Brompton situé au Lac Mégantic dans les Cantons de l'Est ont fait la preuve que les autochtones vivent et occupent la vallée du Saint-Laurent depuis bien avant l'arrivée des Européens. Donc, la science supporte que les peuples autochtones vivent de façon nomade sur le territoire, car l'endroit où furent découverts ces artefacts diffère de la source d'approvisionnement soit, plus de cinq cents kilomètres. Un autre exemple, des gravures sur pierre découverte dans le lit de la rivière St-François à St-Denis-de-Brompton qui date sûrement de la période préhistorique. D'autres gravures furent faites sur les mêmes pierres par d'autres personnes d'origines Européennes qui étaient de passage. J'ai trouvé plusieurs artefacts au cours de ma vie sur les berges de la rivière St-François, notamment un grattoir datant de la période archaïque (entre trois et six mille ans), aussi la pointe d'une lance dont le matériel provient du Mont Kineo qui se situe à une trentaine de kilomètres de la frontière du Québec (Maine). II faut aussi comprendre pour des raisons de nomadisme, que notre nation se déplaçait beaucoup sur le territoire en quête de nourriture de là, un besoin d'avoir un territoire de trois cents par quatre cents milles. 


\section{PÉRIODE CONTACT}

Lors de l'arrivée des premiers Européens sur le territoire de la Nation Abénakis, il était prévu que de grands changements influenceront leur avenir. Premièrement, il était prévu que le système seigneurial serait importé d'Europe. C'est en 1627 qu'a réellement débuté ce mode de distribution des terres lorsque la Compagnie des Cent-Associés obtint le mandat de concéder le territoire de la colonie. En 1854, est aboli au Canada le régime seigneurial, représentant alors un frein à l'industrialisation et au progrès économique. À partir du 18 décembre 1854 , il n'y avait plus de censitaires ni de seigneurs, bien qu'il s'agisse d'une importation conçue pour les Européens, ce mode de distribution de terre a été utilisé pour et par les autochtones qui vivaient dans les sept missions catholiques au Québec.

En effet dans la seigneurie de Saint-François-du-Lac, une parcelle fut concédée en 1700 pour créer une mission Jésuite destinée aux Abénakis de l'endroit et à ceux qui sont venus s'y installer. Puis en 1800, le Conseil de la nation Abénakis débute la concession de ses terres inutilisées aux fins d'agriculture et résidentiel à des non-autochtones. Les Abénakis habitant la seigneurie de Saint-François-du-Lac et de Pierreville, sont-ils réellement seigneurs, puisqu'ils ont eux aussi concédé des terres? Aussi, pouvons-nous dire qu'ils aient un statut différent des autres seigneurs? Selon mes recherches, nous pouvons affirmer que les Abénakis ont bel et bien agi comme des seigneurs, car s'ils n'avaient pas eu ce statut, ils n'auraient pas pu signer en tant que propriétaires légaux des terres en question.

Maintenant pouvons-nous nous poser la question suivante : Estce que cette tactique bien organisée avait pour but d'assimiler les autochtones des missions et de les considérer les autres seigneurs européens de l'époque et que par la suite des événements, la venue de la création de la Loi sur les Indiens? 


\section{LA RENCONTRE DES EUROPÉENS AVEC LES ABÉNAKIS}

Contrairement aux Européens, les Abénakis sont présents depuis longtemps sur le territoire de la côte Est de l'Amérique du Nord qui devient le Nouveau Monde (la Nouvelle-France et une partie maintenant appelée la Nouvelle-Angleterre). Jean de Verrazone (Giovani de Verrazzano), un Florentin au service de François Ier, Roi de France, explore une grande partie de la côte de l'Atlantique, premier pas vers la colonisation Française des Amériques. Les Abénakis sont alors identifiés sous l'appellation «Norumbega» dans les récits des voyageurs et navigateurs. En 1604, Champlain remonte la rivière Penobscot, tout près de l'endroit aujourd'hui appelé Bangor dans l'état du Maine à environ quinze kilomètres de l'océan Atlantique. II fait alors la toute première rencontre avec un de leur chef nommé Norumbega de la nation des Canibas.

(Abénakis). Dans l'histoire de la fondation de l'état du Maine, la nation Abénakis joue un rôle très important depuis les tous premiers établissements.

Les Abénakis étaient connus des colonisateurs comme étant des guerriers et cette expérience a profité aux Français dans le processus de la fondation de la Nouvelle-France. En effet, I'histoire américaine contient de nombreux exemples de la participation des Abénakis au cours de plusieurs affrontements au Sud-Est de la côte Atlantique. Les connaissances des Abénakis au sujet des cours d'eau furent d'une importance capitale pour se rendre sur le fleuve Saint-Laurent qui éventuellement, ouvrira la porte aux explorateurs vers l'Ouest. La rivière Chaudière est une voie d'eau qui a sa source dans l'océan Atlantique et qui de mieux que les Abénakis, qui connaissaient bien leur territoire ancestral, pour guider les explorateurs Français vers l'intérieur des terres au grand fleuve Saint-Laurent.

Les membres de la congrégation des Jésuites ont été ceux qui ont eu le premier contact avec les Abénakis en Nouvelle-France. Ces contacts étaient fréquents, notamment le père Joseph Aubéry qui, à son arrivé, a appris la langue autochtone pour établir son apostolat et naturellement, pour avoir une influence auprès des autorités Abénakis 
et surtout, auprès des autorités Françaises lors de préparation de la défense du territoire et d'empêcher les Anglais de s'établir en territoire Abénakis. Le père Aubéry est bien connu de l'implication des missionnaires dans les campagnes guerrières des Abénakis.

\section{PLAINTES DES CHEFS ABÉNAKIS AUX AUTORITÉS FRANÇAISES.}

Les chefs Abénakis firent maintes plaintes auprès des autorités Françaises concernant les empiètements commis pas les colons sur leurs terres. Ils firent valoir leurs droits et suite à de nombreuses interventions, leurs droits en tant que propriétaires furent entendus et une ordonnance du Marquis de Jonquière fut rédigée le 30 août 1750.

Le Marquis de la Jonquière Commandant de l'Ordre Royal et Militaire de St-Louis, Chef d'Escadre des Armées Navalles, Gouverneur et Lieutenant Général pour le Roy de tout la Nouvelle France, Terres et pays, de la Louisianne.

Étant venu à ma connaissance qu'au préjudice des défenses faites par nos Prédécesseurs en différents temps, plusieurs Français de cette Colonie font faire leur chasse de Martres et de Castors dans la Rivière de la Mission de St-François et dans celles qui en sont proches et qui forment qu'un seul et Même terrein dans la profondeur des terres jusqu'à douze lieues.

Et comme les dittes Rivières et les dittes terres sont réservées pour les Abénakis du dit St-François qui ont seul la faculté d'y aller faire leurs chasse à l'exclusion de tout François jusqu'à douze lieurs, les dits François ne pouvant aller plus loin à la dite chasse. Nous avons défendu et défendront à tout François de quelque qualité et condition qu'ils soient d'aller faire leur chasse dans les dites Rivières et terres jusqu'à douze lieues sous quelque prétexte que ce soit et puisse être à peine de punition et de tout dépenses, dommages et intérêts, envers les dits Abénakis.

Et pour que personne en puisse prétendre cause d'ignorance NOTRE PRÉSENTE ORDONANCE sera lue, publiée et affiché 
au dit St-François et par tout ou besoin sera. En foi de Quoi nous l'avons Signée a cette fait apposer le cachet de nos Armes Contresignée par notre secrétaire Fait à Québec le 30 Aout 1750

Signé LA JONQUIÈRE

En janvier 1800, le conseil des Abénakis et ses représentants constatent que plusieurs lopins de terre ne sont pas utilisés aux fins agricoles. Ils ont décidé d'en concéder pour location à cens et rentes non rachetables. De cette façon, les Abénakis pourraient tirer profit de leurs terres, étant donné que comme pour la plupart des autochtones, ils vivent de pauvreté et sont considérés mineurs au sens de la Loi. Ils dépendent toujours du gouvernement fédéral par la présence de leur agent pour voir à leurs besoins.

\section{GUERRE DE 1812 ENTRE LE CANADA ET LES ÉTATS-UNIS}

La guerre de 1812 fut un tournant important dans l'histoire du Canada plus particulièrement pour nous les Abénakis, car nous avons participé pour défendre dans la partie sud-ouest du territoire non concédée des Abénakis. Plusieurs Abénakis y ont participé et plusieurs ont perdu la vie lors de cette confrontation contre les forces militaires américaines. Par la suite les Abénakis demandèrent au Gouvernement qu'ils soient traités comme tous les autres militaires Canadiens en ce qui concerne des droits de possessions de terre. C'est dans le comté de Durham et de Colleraine dans les Cantons de l'Est que des titres de possession de terre leur ont été accordés par le gouvernement du Canada pour avoir défendu la terre patrie. Depuis plusieurs années aucun Abénakis n'occupe ces terres.

\section{CESSION POUR LOCATION}

Le 7 janvier 1881, une entente pour cession pour location fut acceptée par le Conseil des Abénakis de louer des terres aux fins d'agriculture aux non-autochtones. Une rente annuelle de 30 cents par arpents fut 
acceptée par les parties concernées à condition que, si les locataires ne payent pas leur rente annuelle, les Abénakis reprendront leurs terres. La responsabilité de la collecte des rentes était partie intégrale des responsabilités des agents nommés par les Abénakis. La majorité des agents n'étaient pas des Abénakis et ils ont abusé de leur position pour acquérir des propriétés lors de leur mandat. La rente instituée en 1881 fut payée par les locataires jusqu'en 1912, mais plusieurs circonstances et le manque de fonds pour faire valoir les droits des Abénakis furent ignorés par les autorités fédérales malgré les plaintes régulières des dirigeants Abénakis.

En 1988, je débute les recherches en matière de droits territoriaux et j'obtins le consentement du chef et du conseil pour éclaircir ce dossier. Pendant plusieurs années de recherche et de voyage, je constate que nous sommes toujours propriétaires des terres quifurent concédées pour des fins de location et non de vente. Le conseil accepte ma proposition d'envoyer des factures auprès des municipalités avoisinantes pour nonpaiement de leurs rentes depuis 1912. À ma grande surprise, le chef et le conseil espèrent avoir une entente avec le gouvernement provincial pour obtenir un permis d'avoir un casino sur la réserve à condition que le dossier des rentes en souffrance soit mis de côté puis, ils me remercièrent de mes services par licenciement. Donc après plus de 25 ans de recherches et d'utilisation de fonds publics rien n'est conclu et aucune garantie non plus que nous aurons une compensation pour les terres en location et ni de casino bien sûr. À mon avis, nous n'avons pas à faire de revendications, car nous détenons toujours le droit de possession, car nous n'avons pas vendu.

\section{ORIGINE DU NOM ABÉNAKIS ET NOTRE DIALECTE}

Le nom de la Nation Abénakis est une appellation qui identifie un regroupement de plusieurs nations qui vivent sur le territoire ancestral depuis des millénaires. Les historiens, les anthropologues et même les linguistes ont eu beaucoup de difficultés à "nous décortiquer» en quelque sorte : quelle famille appartient à quelle nation. Nous, 
la famille des OBomsawin, sommes descendants d'un Sachem du nom de Bomazeen qui a vécu dans la mission de Norridgewok où le missionnaire Jésuite Sébastien Rasle, avait son domicile. Donc, nous sommes plus particulièrement des Norridgewock vivant maintenant à Odanak. Les autres familles de ma communauté appartiennent à différentes nations autochtones et non-autochtones.

Mes grands-parents parlaient principalement l'Abénakis qui est une langue commune de toutes les tribus d'origines Algonquiennes en Amérique du Nord.

Étant de fort jeune âge, j'ai demandé à mon grand-père Joseph OBomsawin : «Veux-tu me montrer à parler abénakis? ॥ II me dit en souriant : "Réjean, je peux t'enseigner notre langue, mais pour te trouver de l'emploi ce sera difficile, personne va te comprendre. Ce serait plus pratique que tu apprennes à parler l'anglais ». II ajoute : "Tu sais Réjean, tu dois savoir par contre que si tu parles notre langue Abénakis, tu pourras te faire comprendre par toutes les tribus d'Amérique, à l'exception des Iroquois qui n'ont aucun lien avec nous parce qu'ils proviennent de l'Amérique du Sud. Ils sont des sédentaires et cultivateurs au contraire de nous, car nous sommes des nomades et notre moyen de subsistance est la chasse, la pêche, la trappe et la cueillette et nous sommes toujours en mouvement sur le territoire».

\section{WAMPUM : ORIGINE, UTILISATION ET ALLIANCE}

En 1661, mes ancêtres font un don à la Cathédrale de Chartres d'une des plus volumineuses ceintures de Wampum, fabriquées à la main, composée en majorité de perles mauves, ayant une dimension qui compte plus de 20000 perles de coquillages. Selon la tradition orale, treize ceintures furent démantelées pour fabriquer cette ceinture.

Quelle est l'origine du mot Wampum? C'est un mot de la Nation Wampanoag de la région de Cape Cod où se trouvait le plus gros approvisionnement en quahog, une espèce de palourde (clam) pour fabriquer les perles de Wampum (Wôbonbial) pour ensuite les tisser 
sur des ceintures servant pour les cérémonies. Lors des raids dans nos communautés, les Anglais et leurs alliés ont pillé les ceintures qui se trouvaient dans nos communautés. Les confrontations furent féroces, car nous les gardions et les protégions. De ce fait, les étrangers étaient persuadés que ces ceintures de coquillages étaient notre monnaie. II ne faut pas oublier qu'à cette époque les nations d'Europe étaient à la recherche de métaux précieux. Par la suite, ces ceintures furent considérées de grande valeur.

II y a des ceintures historiques comme celles fabriquées par les Iroquois qui représentent des aide-mémoires reliés à des événements historiques. Les plus anciennes, comme les nôtres, sont des ceintures scientifiques utilisées pendant les cérémonies.

\section{APPRENTISSAGE ET PRATIQUE DES CÉRÉMONIES SACRÉES}

En 1987, suite à ma participation à ma première cérémonie du Calumet avec un ainé du nom de Art Salomon un autochtone de la nation Anishnabe, je décide de faire un retour aux sources et voilà que débute mon apprentissage des rites et cérémonies. Au fil des ans, après avoir appris d'un guérisseur Mi'kmaq du nom de David Gehue je commence à mettre en pratique ce que j'ai appris tout au long de ces années soit la cérémonie de fumigation, du calumet, de la loge à transpirer et pour terminer la tente tremblante. Cet enseignement est non seulement très rigoureux, mais le plus difficile est la solitude. Après plus de 30 ans de pratique ancestrale et traditionnelle, je suis heureux que des grand-mères m'aient demandé de présider des cérémonies de nom traditionnel pour leurs petites filles. Dernièrement depuis les deux dernières années j'ai eu l'honneur de faire le rite de purification pour deux funérailles de personne de ma communauté que leur famille était tellement fière de connaitre ce rite qui leur appartient culturellement.

Le calumet (wdamôgan) est utilisé depuis plusieurs siècles par les Abénakis et amené par les Renards. 
Les Renards nous ont rendu visite en 1770 pour nous demander de quitter nos terres pour les rejoindre au Wisconsin, car ils craignaient que nous soyons anéantis à cause des guerres et des maladies. Les Abénakis les remercièrent de leur offre et en s'adressant à eux ils leur dirent : «Nous ne pouvons pas quitter la chair qui contient le corps de nos ancêtres».

Donc, ayant appris à propos de l'histoire du Calumet et de son utilisation, je l'utilise lors de plusieurs cérémonies sacrées. Le Calumet est composé d'une pièce de bois pour le chalumeau et d'un bol en pierre. Le chalumeau représente les arbres, le bol la terre et le tabac qui s'y consume, représente le magma qui brûle au centre de la Terre. Donc, lorsque ces deux pièces sont réunies, le Ciel et la Terre, tout est possible, dépendamment de la demande et des instructions qui seront dites à l'officiant. Le calumet que je possède a été sculpté par feu Guy Sioui (Wendate-Abénakis) un artisan de notre communauté. Ce calumet représente les deux clans principaux (Awassos, Tolba) et le totem (Kabasa) de notre communauté. J'utilise ce calumet seulement dans des occasions très spéciales. Si une personne désire participer à une cérémonie du calumet, du tabac m'est offert et des instructions précises sont données à la personne qui désire participer. II y a plusieurs types de calumets pour différentes utilisations, que ce soit personnel ou communautaire.

Lors de mon apprentissage et ayant parlé avec mon père, feu Albert OBomsawin, à ce sujet, me dit que de respecter le calumet est très important, car c'est un objet sacré et quand tu danses en son honneur, tu dois le faire avec humilité, respect et de façon solennelle.

Donc, malgré les siècles passés, la danse se pratique encore à Odanak. La seule différence de ceux et celles qui la pratiquent c'est qu'ils ne le font pas comme une cérémonie sacrée, mais plutôt, comme une danse folklorique pour plaire aux spectateurs. 


\section{VIOLATION DE MES DROITS ET PROFANATION DU SITE SACRÉ}

En septembre 2016, les travaux de coupe à blanc de la forêt où se trouve le site de prière et de cérémonie utilisé pour la commémoration du massacre des Abénakis à Odanak par le Major Robert Roger le 4 octobre 1759, tuant vieillards, femmes et enfants Abénakis. Pendant une période, plusieurs cérémonies se sont tenues à l'endroit où la route est bâtie aujourd'hui et aussi une multitude d'offrandes pour des prières furent déposées à cet endroit à proximité de la loge de sudation. Après plus de sept ans d'efforts, sans me consulter et sans me demander mon approbation en tant qu'élu et en tant que chef spirituel, le chef de notre communauté et le conseil passent à la phase de début des travaux par la destruction de la forêt sans ce soucier de faire une étude environnementale, archéologique ni de prendre en considération des sépultures possibles à cet endroit sacré, ni aucune consultation publique expliquant clairement le but de cette destruction. Les moments que nous avons vécus furent très difficiles à la présence de machineries lourdes détruisant la forêt et profanant ce site en détruisant les offrandes sacrées de tabac, de nourriture et de prières pour les ancêtres.

L'Article 35 de la Constitution canadienne constitue la protection des droits autochtones, dont celle de religion. Je contacte Radio Canada télévision de la région de la Mauricie pour couvrir l'événement. La journaliste me dit qu'elle doit parler aux chef et conseil à ce sujet pour savoir leur version des faits.

Malheureusement, rien ne passe aux nouvelles le même jour et plus aucune communication avec la journaliste ni du journaliste local. Donc, je contacte l'honorable Premier Ministre Justin Trudeau ainsi que la Ministre des Affaires Indiennes et du Nord Carolyn Bennet de l'aviser que mes droits de religion en référence à l'Article 35 sont lésés et que je souhaite que les travaux cessent. Les jours et les semaines passent, et pendant ce temps la destruction s'amplifie et l'installation de tuyaux des services publics souterrains se fait sur une grande période quotidiennement ce qui joue sur notre santé et notre moral 
de voir que même les hautes instances ne prennent pas cette plainte au sérieux. Alors en dernière instance je dépose une plainte officielle auprès de la Commission canadienne des droits de la personne en tant que chef spirituel et que mes droits et pratiques sont lésés et de la destruction de lieux sacrés et de me limiter de pratiquer les rites sacrés à cet endroit. Nous attendons la prochaine étape de la commission canadienne des droits de la personne pour savoir la marche à suivre malgré que la destruction soit complétée.

\section{CONCLUSION}

Aujourd'hui, au 21e siècle il est possible d'apprendre, de connaitre et surtout de continuer à pratiquer nos rites sacrés malgré toutes les embuches et surtout de pouvoir l'enseigner à tous ceux et celles qui désirent apprendre ce qui leur appartient, qu'importe le lieu, l'origine ou l'alliance avec d'autres nations du monde. Tout ce que je demande avec humilité et respect est de continuer de prier pour la protection de la Terre, de l'Eau, de l'Air et de notre Humanité.

Que Kchi Niwaskw vous protège et vous garde

Réjean OBomsawin

Wawasi Piônisak (Chef spirituel) Abénakis 


\section{Preservemos nossos ritos ancestrais Wôbanaki}

Réjean Obomsawin ${ }^{1}$

Tradução: Bruce Gilbert² e Priscylla Monteiro Joca ${ }^{3}$

\section{BIENVENUE, KOLIPAIÔ, BEM- VINDO, WELCOME}

No território ancestral da nação Abénakis em memória de nossos respectivos antepassados que viveram juntos em harmonia por várias gerações.

Agradeço ao Dr. Bruce Gilbert, Professor de Filosofia, Artes e Justiça Social na Universidade de Bishop por ter organizado e nos ter convidado, minha esposa Jacinthe Laliberté e eu, assim como todos aqueles que colaboram e participam deste evento histórico, um grande sucesso no território Abénakis.

É muito importante entender que, para ser Abénakis e praticar, proteger e preservar nossas tradições, nossos costumes e nossas cerimônias não é de todo a imagem que é transmitida. Minha comunidade, entre outras, é um exemplo flagrante do impacto da "Lei sobre os Índios" e das diferentes maneiras de aculturar um povo. Nem sempre são erros cometidos por não-indígenas, mas a influência política e so-

1 Wawasi Piônisak (Chef Spirituel). Conférence présentée au Colloque Droits Sociaux et Environnementaux à l'université Bishop. Odanak, Le 20 octobre 2017.

2 Professor da Universidade de Bishop, Sherbrooke, Canadá.

3 Doutoranda em Direito na Universidade de Montreal, Montreal, Canadá. 
cial de pessoas indígenas que, infelizmente, desconhecem a beleza das tradições orais, dos contos, das lendas que são a alma da minha comunidade, que não pode ser comprado, mas merece.

Antes, o espírito de ajuda mútua era uma prática comum dos nossos costumes. Agora, eu descobri, para minha grande surpresa, que as classes sociais ainda existem em Odanak. Essa nova maneira de pensar e de agir foi iniciada por pessoas que não faziam parte de nossa cultura e que se apresentaram de maneiras diferentes, seja através do comércio de cestarias ou simplesmente através do casamento, a fim de ter acesso a posições políticas importantes na minha comunidade. Este modo de pensar e agir é palpável e se manifesta seja controlando a economia, ou através da malediscência, do individualismo, tudo para assegurar que os valores baseados no Sagrado, de acordo com nossos ensinamentos, não sejam acessíveis e, assim, destruam os locais Sagrados como o que fica perto de minha casa, em setembro de 2017. Dessa maneira, se envia uma mensagem muito clara às gerações futuras de que as tradições do Sagrado não são bem-vindas em nossa comunidade. Eles afirmam à nossa comunidade, de modo a impor, que aquilo é uma coisa do passado que, agora, se tornou folclore para os turistas. É assim que dizem ao público em geral que nos esquecemos de nossas tradições, o que é falso.

Eu acredito que é sempre relevante fazer reviver e sair das sombras as práticas dos sagrado Abénakis e outros. A reconciliação deve ser feita em nossa comunidade, por e para nosso povo. Descobri ao longo dos anos que descobrir a pessoa que sou e minhas origens franco-Abénakis faz parte de um "todo" do que sou, como ser humano, e de viver em harmonia com tudo que me redeia. Nossa história, nossas tradições, nossos ritos e nosso território contêm muitos tesouros a serem descobertos e protegidos para as gerações futuras e apreciadas com outras nações que nos honram com suas visitas ao território Abénakis.

Tenho muito orgulho de poder compartilhar com vocês sobre o que somos e o que aprendi sobre nossas tradições e cerimônias nos últimos trinta anos. 


\section{INTRODUÇÃO}

Neste tópico, discutirei o período pré-contato que descreve os movimentos no território para atender as necessidades de nosso povo Abénakis e o período de contato que relata os primeiros encontros com os europeus e sua estrutura do território que adotamos. Eu também descrevo o reconhecimento dos Abénakis pela França em 1750 e a concordância dos Abénakis, que se tornaram os senhores em suas terras, de conceder, através do aluguel, terras aos colonos para a agricultura e necessidades residenciais. Enquanto isso, aconteceu a guerra de 1812 entre o Canadá e os Estados Unidos. Continuo descrevendo a origem dos Abénakis e seus costumes. Por fim, falarei sobre o meu aprendizado e prática de cerimônias sagradas antigas, bem como sobre minhas motivações para preservar nossa cultura e costumes que se fragilizam diante de ações irrefletidas por parte de certas pessoas.

\section{PERÍODO PRÉ-CONTATO}

Outras gravuras foram feitas nas mesmas pedras por outras pessoas de origem européia que estavam de passagem. Encontrei muitos artefatos em minha vida nas margens do rio St-François, incluindo um escavador do período arcaico (entre três e seis mil anos), assim como a ponta de uma lança cujo material provém do Monte Kineo que fica a cerca de trinta quilômetros da fronteira do Quebec (Maine). Também é necessário compreender que, por razões de nomadismo, que nossa nação estava se movendo muito no território em busca de comida, daí a necessidade de ter um território de trezentos por quatrocentos milhas.

A nação Abénakis vive no território desde tempos imemoriais, há mais de doze mil anos de idade. As últimas escavações arqueológicas (2008) em Brompton situado no Lago Mégantic, em Cantons de l'Est, demonstraram que os indígenas vivem e ocupam o Vale de Saint-Laurent desde muito antes da chegada dos europeus. Assim, a ciência afirma que os povos indígenas vivem de modo nômade no território, porque o local onde esses artefatos foram descobertos difere 
da fonte de suprimento, localizada a mais de quinhentos quilômetros. Outro exemplo são as gravuras sobre pedra descobertas no leito do rio St-François, em St-Denis-de-Brompton, que certamente remontam ao período pré-histórico. Outras gravuras foram feitas nas mesmas pedras por outras pessoas de origem européia que estavam de passagem. Encontrei muitos artefatos em minha vida nas margens do rio St-François, incluindo um raspador que data do período arcaico (entre três e seis mil anos), também a ponta de uma lança cujo material provém do Monte Kineo, que fica a cerca de trinta quilômetros da fronteira de Quebec (Maine). É preciso também que se compreendaque, por razões do nomadismo, nossa nação se movia muito no território em busca de comida, daí a necessidade de ter um território de trezentos e quatrocentos quilômetros.

\section{PERÍODO DE CONTATO}

Quando os primeiros europeus chegaram no território da Nação Abénakis, esperava-se que grandes mudanças influenciassem o futuro. Primeiramente, foi previsto que o sistema senhorial seria importado da Europa. Foi em 1627 que este método de distribuição de terras realmente começou quando a Companhia de Cem-Associados obteve o mandato para conceder o território da colônia. Em 1854, o regime senhorial foi abolido no Canadá, representando assim um freio à industrialização e ao progresso econômico. A partir de 18 de dezembro de 1854, não havia mais censitários e nem senhores, embora fosse uma importação projetada para os europeus, esse método de distribuição de terras era usado para e pelos indígenas que viviam nas sete missões católicas no Quebec.

De fato, no senhorio de Saint-François-du-Lac, uma parcela foi concedida em 1700 para criar uma missão jesuíta destinada aos Abénakis do lugar e para aqueles que vieram se estabelecer lá. Então, em 1800, o Conselho da Nação Abénakis começou a conceder suas terras não utilizadas para uso agrícola e residencial aos não-indígenas. Os Abénakis que vivem no senhorio de Saint-François-du-Lac e Pierreville são realmente senhores, desde que eles também concederam terra? 
Também, podemos dizer que eles têm um status diferente dos outros senhores? De acordo com minha pesquisa, podemos afirmar que os Abénakis de fato agiram como senhores, porque se eles não tivessem esse status, eles não teriam sido capazes de assinar como proprietários legais das terras em questão.

Agora, podemos nos fazer a seguinte pergunta: essa tática bem organizada visava assimilar os indígenas das missões e considerar os outros senhores europeus da época e, posteriormente, aqueles eventos ensejaram a criação da Lei sobre os Índios?

\section{O ENCONTRO DOS EUROPEUS COM OS ABÉNAKIS}

Contrariamente aos europeus, os Abénakis estão presentes há muito tempo no território da costa leste da América do Norte que se torna o Novo Mundo (a Nova França e uma parte hoje chamada de Nova Inglaterra). Jean de Verrazone (Giovani de Verrazzano), um florentino a serviço de Francisco I, rei da França, explorou grande parte da costa atlântica, que foi o primeiro passo para a colonização francesa das Américas. Os Abénakis são então identificados sob o nome "Norumbega" nas histórias de viajantes e navegadores. Em 1604, Champlain subiu o rio Penobscot, perto do lugar agora chamado Bangor, no estado do Maine, a cerca de quinze quilômetros do Oceano Atlântico. Ele então fez a primeira reunião com um dos seus chefes chamado Norumbega da nação Canibas.

(Abénakis). Na história da fundação do estado do Maine, a nação Abénakis desempenha um papel muito importante desde os primeiros assentamentos.

Os Abénakis eram conhecidos pelos colonizadores como guerreiros e essa experiência beneficiou os franceses no processo de fundação da Nova França. De fato, a história americana contém inúmeros exemplos da participação dos Abénakis durante vários confrontos no sudeste da costa atlântica. O conhecimento dos Abénakis sobre os cursos d'água foram de suma importância para chegar ao rio Saint-Laurent 
que, eventualmente, abriu a porta para os exploradores em direção ao oeste. $O$ rio Chaudière é um canal que tem sua origem no Oceano Atlântico e quem seria melhor que os Abénakis, que conheciam bem seu território ancestral, para guiar os exploradores franceses para 0 interior sob o grande rio Saint-Laurent.

Os membros da congregação jesuíta eram aqueles que tiveram o primeiro contato com os Abénakis na Nova França. Estes contactos eram frequentes, especialmente o Padre Joseph Aubéry que, à sua chegada, aprendeu a língua indígena a fim de estabelecer o seu apostolado e, naturalmente, ter influência junto às autoridades Abénakis e, especialmente, junto às autoridades francesas na preparação da defesa do território e para impedir que os ingleses se estabelecessem no território dos Abénakis. O padre Aubéry é bem conhecido pelo envolvimento de missionários nas campanhas guerreiras dos Abénakis.

\section{RECLAMAÇÕES DOS CHEFES ABÉNAKIS ÀS AUTORIDADES FRANCESAS}

Os chefes Abénakis fizeram numerosas reclamações às autoridades francesas sobre as invasões cometidas pelos colonos sobre suas terras. Eles reivindicaram seus direitos e, depois de muitas intervenções, seus direitos como proprietários foram ouvidos e uma ordem do Marquês de Jonquière foi elaborada em 30 de agosto de 1750.

O Marquês de la Jonquière, Comandante da Ordem Real e Militar de St-Louis, Chefe da Ala Forças Navais, Governador e Tenente-General para o Rei de toda a Nova França, Terras e país, da Louisiana.

Tendo chegado ao meu conhecimento que, em detrimento das defesas feitas pelos nossos Predecessores em diferentes épocas, vários franceses desta Colônia têm feito sua caça de martas e castores no rio da missão de St-François e em áreas próximas e que formam uma só e mesma terra na profundidade das terras até doze léguas.

E como ditos Rios e ditas terras estão reservadas para os Abénakis do referido St-François que são os únicos que 
tem a faculdade de fazer suas caças, excluindo todo francês até doze léguas, os ditos franceses não podem ir além da dita caça. Nós temos defendido e defendemos diante de todo francês, seja qual for a sua qualidade e condição, que eles podem caçar nos referidos Rios e terras acima de doze léguas sob qualquer pretexto que seja, podendo ser severamente punidos e responsáveis por todas as despesas, danos e juros para com os referidos Abénakis.

E para que ninguém possa reclamar causa de ignorância NOSSA ORDONANÇA ATUAL será lida, publicada e afichada no dito St-François e será por todos ou para toda necessidade. Na fé do Que nós assinamos para este fato afixamos o selo de nossas armas referendadas por nosso secretário datado em Quebec no dia 30 de agosto de 1750. Assinado LA JONQUIËRE

Em janeiro de 1800, o conselho dos Abénakis e seus representantes constataram que vários terrenos não eram utilizados para fins agrícolas. Eles decidiram conceder os terrenos para locação em anuidades não-resgatáveis. Desta forma, os Abénakis poderiam se beneficiar de suas terras, uma vez que, como a maioria dos indígenas, vivem na pobreza e são considerados menores de acordo com o significado da lei. Eles ainda dependem do governo federal pela presença de seu agente para cuidar de suas necessidades.

\section{GUERRA DE 1812 ENTRE O CANADÁ E OS ESTADOS UNIDOS}

A guerra de 1812 foi um importante ponto de viragem na história do Canadá, especialmente para nós, os Abénakis, porque nós participamos para defender a parte sudoeste do território não-cedido Abénakis. Vários Abénakiss participaram e muitos perderam suas vidas neste confronto contra as forças militares americanas. Posteriormente, os Abénakis demandaram ao governo que eles fossem tratados como qualquer outro militar canadense com relação aos direitos de propriedade da terra. Foi no Condado de Durham e de Colleraine, nos municípios do leste, que os títulos de propriedade da terra lhes foram 
concedidos pelo governo do Canadá para ter defendido a terra pátria. Durante vários anos, nenhum Abénakiss ocupou essas terras.

\section{CESSÃO POR LOCAÇÃO}

Em 7 de janeiro de 1881, um acordo de arrendamento foi aceito pelo Conselho Abénakis para arrendar terras para agricultura a não-indígenas. Um aluguel anual de 30 centavos de dólar por acre foi aceito pelas partes envolvidas desde que, se os inquilinos não pagassem seu aluguel anual, os Abénakiss retomariam suas terras. A responsabilidade pela coleta das anuidades era parte integrante das responsabilidades dos agentes indicados pelos Abénakis. A maioria dos agentes não eram Abénakis e eles abusaram de sua posição para adquirir propriedades durante o seu mandato. $\mathrm{O}$ aluguel instituído em 1881 foi pago pelos locatários até 1912, mas várias circunstâncias e a falta de recursos para assegurar os direitos dos Abénakis foram ignoradas pelas autoridades federais, apesar das queixas regulares dos líderes Abénakis.

Em 1988, iniciei pesquisas sobre direitos territoriais e obtive o consentimento do chefe e do conselho para esclarecer este assunto. Durante os anos de pesquisa e viagens, eu constatei que nós somos ainda proprietários das terras que foram cedidas para locação e não para venda. O conselho aceitou minha proposta de enviar faturas aos municípios vizinhos pelo não-pagamento de suas anuidades desde 1912. Para minha surpresa, o chefe e o conselho esperavam realizar um acordo com o governo provincial para obter uma permissão para ter um casino na reserva desde o dossiê sobre as anuidades atrasadas seja deixado de lado e, em seguida, eles me agradeceram pelos meus serviços por demissão. Assim, depois de mais de 25 anos de pesquisa e utilização de fundos públicos, nada está concluído e não há garantias de que teremos uma compensação pelas terras alugadas e nem que teremos nenhum cassino, é claro. Na minha opinião, nós não temos que fazer reclamações, porque ainda temos o direito de posse, porque não vendemos. 


\section{ORIGEM DO NOME ABÉNAKIS E NOSSO DIALETO}

O nome da Nação Abénakis é uma denominação que identifica um agrupamento de várias nações que viveram em território ancestral desde milênios. Historiadores, antropólogos e até lingüistas tiveram grande dificuldade em nos "analisar" de certa forma: que família pertence a qual nação. Nós, a família OBomsawin, somos descendentes de um Sachem chamado de Bomazeen que viveu na missão Norridgewok onde o missionário jesuíta Sébastien Rasle tinha sua casa. Então, nós somos mais especificamente Norridgewock agora vivendo em Odanak. As outras famílias da minha comunidade pertencem a diferentes nações indígenas e não-indígenas.

Meus avós falavam principalmente Abénakis, que é uma língua comum de todas as tribos de origem algonquiana na América do Norte.

Quando era muito jovem, perguntei ao meu avô Joseph Obomsawin: "Você quer me mostrar como falar Abénakis?" Ele disse para mim com um sorriso: "Réjean, eu posso te ensinar a nossa língua, mas para você encontrar um trabalho será difícil, ninguém vai te entender. Seria mais conveniente que você aprendesse a falar em inglês ». Ele acrescentou: "Você sabe Réjean, você deve saber, por outro lado, que se você falar nossa língua Abénakis, você será capaz de se fazer entender por todas as tribos da América, exceto os Iroquois que não têm conexão conosco porque eles vêm da América do Sul. Eles são sedentários e cultivadores, diferentes de nós, porque somos nômades e nosso meio de vida é a caça, a pesca, a captura e a coleta e estamos sempre em movimento."

\section{WAMPU : ORIGEM, UTILIZAÇÃO E ALIANÇA}

Em 1661, meus antepassados doaram à Catedral de Chartres um dos maiores cintos de Wampum feitos à mão, composto principalmente de pérolas lilás, com uma dimensão que conta mais de 20.000 pérolas 
de conchas. Segundo a tradição oral, treze cintos foram desmontados para fazer este cinturão.

Qual é a origem da palavra Wampum? Esta é uma palavra da Nação Wampanoag da região de Cape Cod, onde há a maior oferta de quahog, uma espécie de molusco (clam) para fabricar as pérolas de Wampum (Wôbonbial) para, em seguida, tecê-las em forma de cintos para as cerimônias. Durante incursões em nossas comunidades, os ingleses e seus aliados saquearam os cinturões que se encontravam em nossas comunidades. Os confrontos foram ferozes porque os mantivemos e os protegemos. Como resultado, os estrangeiros estavam convencidos de que esses cintos de conchas eram nossa moeda. Não se deve esquecer que, naquela época, as nações da Europa estavam em busca de metais preciosos. Posteriormente, esses cintos foram considerados de grande valor.

Há cinturões históricos como os fabricados pelos Iroquois que representam lembretes relacionados a eventos históricos. Os mais antigos, como os nossos, são cinturões científicos usados durante as cerimônias.

\section{APRENDIZAGEM E PRÁTICA DE CERIMÔNIAS SAGRADAS}

Em 1987, após minha participação em minha primeira cerimônia em Calumet com um ancião chamado Art Salomon, um indígena da nação Anishnabe, decidi fazer um retorno às origens e foi então que começou minha aprendizagem dos ritos e cerimônias. Ao longo dos anos, depois de aprender com um curador Mi'kmaq chamado de David Gehue, eu comecei a praticar o que aprendi ao longo dos anos, seja a cerimônia de fumigação, do cachimbo, da cabana à transpirar e, para terminar, a tenda trêmula. Esse ensinamento não é somente muito rigoroso, mas o mais difícil é a solidão. Depois de mais de 30 anos de prática ancestral e tradicional, fico feliz que as avós me demandam para presidir as cerimônias de nome tradicional para suas netas. Recentemente, ao longo dos últimos dois anos, tive a honra de realizar o 
rito de purificação para dois funerais de pessoas da minha comunidade, e suas famílias estavam muito orgulhosas de conhecer esse ritual que lhes pertence culturalmente.

O cachimbo (wdamôgan) tem sido usado por vários séculos pelos Abénakis e trazidos pelas raposas.

As Raposas nos visitaram em 1770 para nos pedir para deixarmos nossas terras e nos unirmos a elas em Wisconsin, porque eles temiam que nós fossemos destruídos por guerras e doenças. Os Abénakis agradeceram a oferta e Ihe disseram: "Não podemos deixar a carne que contém os corpos de nossos ancestrais".

Então, tendo aprendido sobre a história do Cachimbo e o seu uso, eu o utilizo em várias cerimônias sagradas. O Cachimbo consiste em um pedaço de madeira para a tocha e uma tigela de pedra. A tocha representa as árvores, a taça, a terra e o fumo que se consomem, representa o magma que arde no centro da Terra. Então, quando essas duas partes estão juntas, Céu e Terra, tudo é possível, dependendo da solicitação e das instruções que serão dadas ao oficiante. O cachimbo que eu possuo foi esculpido pelo falecido Guy Sioui (Wendate-Abénakiss), um artesão de nossa comunidade. Este cachimbo representa os dois principais clãs (Awassos, Tolba) e o totem (Kabasa) da nossa comunidade. Eu uso este cachimbo apenas em ocasiões muito especiais. Se uma pessoa deseja participar de uma cerimônia do cachimbo, o tabaco é oferecido a mim e instruções específicas são dadas à pessoa que deseja participar. Existem vários tipos de cachimbos para diferentes usos, sejam pessoais ou comunitários.

Durante meu aprendizado e tendo falado com meu pai, o falecido Albert OBomsawin, sobre esse assunto, ele me disse que respeitar o cachimbo é muito importante, porque é um objeto sagrado e quando você dança em sua homenagem, você tem que fazer isso com humildade, respeito e solenemente.

Portanto, apesar dos séculos passados, a dança ainda é praticada em Odanak. A única diferença daqueles que a praticam é que eles não 
fazem mais isso como uma cerimônia sagrada, mas sim como uma dança folclórica para agradar os espectadores.

\section{VIOLAÇÃO DE MEUS DIREITOS E PROFANAÇÃO DO LOCAL SAGRADO}

Em setembro de 2016, houve trabalhos de corte de clareira na floresta onde se encontra o local de oração e cerimônia utilisado para rememorar o massacre dos Abénaki em Odanak pelo major Robert Roger no dia 4 de outubro de 1759, matando velhos, mulheres e crianças Abénakis. Durante um período, várias cerimônias foram realizadas no local onde a estrada é construída hoje e também uma multidão de oferendas para orações foram depositadas neste local próximo à da cabana de transpiração. Depois de mais de sete anos de esforços, sem me consultar e pedir minha aprovação como eleito e como líder espiritual, o chefe de nossa comunidade e o conselho passaram à fase inicial dos trabalhos para destruição da floresta sem se preocupar em fazer um estudo ambiental ou arqueológico e sem levar em consideração as possíveis sepulturas neste lugar sagrado, nem qualquer consulta pública explicando claramente o propósito dessa destruição. Os momentos que vivemos foram muito difíceis pela presença de máquinas pesadas destruindo a floresta e profanando este local, destruindo as ofertas sagradas de tabaco, comida e orações pelos antepassados.

O Artigo 35 da Constituição canadense constitui a proteção dos direitos indígenas, incluindo o de religião. Entrei em contato com a emissora de televisão Radio Canada na região de Mauricie para cobrir o evento. $O$ jornalista me disse que ela precisaria conversar com os chefes e o conselho sobre esse assunto para saber sua versão dos fatos.

Infelizmente, nada passou nas notícias daquele mesmo dia e não há mais nenhuma comunicação com o a jornalista nem o jornalista local. Então, entrei em contato com o Sr. Primeiro-Ministro Justin Trudeau e o com a Ministra de Assuntos Indígenas e do Norte, Carolyn Bennet, para avisar que meus direitos de religião, nos termos do artigo 35, foram feridos e que eu espero que os trabalhos cessassem. Os dias e 
as semanas passam, e durante este tempo a destruição se amplifica e a instalação de tubulações de serviços públicos subterrâneos é feita diariamente, em um grande período, que impacta em nossa saúde e nosso moral ao ver que mesmo as altas autoridades não levam esta queixa a sério. Então, em último recurso, eu depositei uma denúncia formal à Comissão Canadense de Direitos Humanos, como líder espiritual, por meus direitos e práticas que foram prejudicados, e pela destruição de lugares sagrados, e por me limitar de praticar os ritos sagrados nesse lugar. Estamos aguardando a próxima etapa da Comissão Canadense de Direitos Humanos para saber o que fazer em seguida, mesmo que a destruição esteja completa.

\section{CONCLUSÃO}

Hoje, no século XXI, é possível aprender, conhecer e especialmente continuar a praticar nossos ritos sagrados apesar de todas as armadiIhas e, especialmente, de poder ensinar a todos aqueles que desejam aprender o que lhes pertence, que não importa o lugar, a origem ou a aliança com outras nações do mundo. Tudo o que peço com humildade e respeito é continuar a rezar pela proteção da Terra, da Água, do Ar e da nossa Humanidade.

Que Kchi Niwaskw vos proteja vos guarde

Réjean OBomsawin

Wawasi Piônisak (Chef spirituel) Abénakis 